\title{
Una definición típica de los numerales: la de cálculo aritmético
}

\author{
José-ÁlVARo Porto DAPENA \\ Universidad da Coruña
}

Existe una creencia bastante generalizada según la cual una definición -incluida la lexicográfica-, si está bien formulada, no podrá ser modificada o sustituida por otra. De ahí precisamente la impunidad con que las definiciones de los diccionarios suelen con frecuencia pasar de unos a otros, a veces al pie de la letra, sin que, por ello, nadie se escandalice ni siquiera se atreva a hablar de plagio. Desde luego, copiar, por ejemplo, del $D R A E$ ha sido, como es sabido, práctica habitual en la lexicografía española, aunque, por otro lado, tampoco la Academia se haya quedado a veces manca copiando de aquí y de allá. ${ }^{1}$ Sería sin duda altamente interesante cotejar unos diccionarios con otros y descubrir así las influencias que, sobre todo en este aspecto, se han venido produciendo entre ellos a lo largo de los tiempos, investigación que por cierto nos aportaría interesantísimos materiales para la historia interna de nuestra lexicografía, que, evidentemente, está por hacer.

Aun admitiendo que pueden producirse coincidencias no necesariamente atribuibles a influencia ajena, pues una palabra puede dejar muy poco margen de definición, existen de hecho muchísimos casos en que ésta puede adoptar múltiples formas sin que ninguna de ellas sea necesariamente mejor ni peor que las otras. Piénsese, por ejemplo, en un verbo semánticamente tan sencillo como morir, que podría ser definido perfectamente de las siguientes maneras:

1. Dejar de vivir

2. Perder la vida

3. Llegar al término de la vida

4. Terminar la vida

5. Despedirse de este mundo

6. Exhalar el espíritu,

etc., sin contar, naturalmente, con posibilidades sinonímicas -independientemente de matices pragmáticos-como fallecer, finar, cascar, diñar, estirar la pata, desaparecer con otro largo etcétera.

${ }^{1}$ Solo por citar dos grandes maestros de la lexicografía que copian del $D R A E$, recordemos a Casares, que en su famoso Diccionario ideológico reproduce al pie de la letra la mayor parte de las definiciones académicas, y, antes que él, Cuervo se aprovecha asimismo con frecuencia de esa misma fuente en los dos primeros tomos de su Diccionario de construcción y régimen de la lengua castellana. Por su parte la Academia, como es sabido, no tuvo en su día escrúpulo en incorporar, para los salmantinismos, materiales de Lamano, contenidos en el «Vocabulario» de su obra El dialecto vulgar Salmantino, o los de Borao (Diccionario de voces aragonesas) para los aragonesismos, solo por citar también un par de casos. 
Precisamente, en el presente trabajo quiero llamar la atención sobre un tipo especial de definición, la que propongo llamar de cálculo aritmético, consistente, como su denominación indica, en formular una operación matemática como definiens o paráfrasis del definido, el cual en este caso viene representado siempre por un numeral cardinal. Tal tipo de definición puede por cierto ofrecer múltiples posibilidades, que a primera vista deberían aumentar a medida que el número definido es más alto o hace referencia a una mayor cantidad de unidades. Y así, para un número relativamente bajo como cuatro, podríamos tener, entre otras, estas definiciones:

\section{Tres más uno \\ 8. Dos y dos \\ 9. Dos veces dos (o Dos por dos) \\ 10. Cinco menos uno \\ 11. Mitad de ocho (u Ocho partido por dos)}

etc. En principio podría, desde luego, servir cualquier tipo de operación cuyo resultado fuera precisamente el número definido, lo cual abre, por tanto, un conjunto de posibilidades prácticamente infinito. En la práctica, sin embargo, aunque, como vamos a ver, existen fuertes discrepancias entre los diccionarios a la hora de definir los numerales, se producen de hecho múltiples coincidencias, si no en las definiciones mismas -que también-, sí al menos en el procedimiento o procedimientos aritméticos adoptados, que, salvo excepciones, se reducen prácticamente a dos: la suma junto a lo que en el fondo es una pura variedad de ésta, la multiplicación, lo que hace que este tipo de definición no sea en la mayoría de los casos más que una variedad de la que hace ya más de veinte años bauticé con el nombre de definición aditiva (Porto Dapena 1980: 318).

\section{LOS DEFINIENDA: NUMERALES CARDINALES}

Así pues, el tipo de definición que vamos a estudiar corresponde a los llamados numerales cardinales, sobre todo en su función de pronombres, sea en su uso adjetivo o, como prefieren llamarle algunos, determinante, sea en su uso nuclear o sustantivado; es decir, en contextos del tipo

12. Ayer compré dos libros

13. Me regalaron varias novelas, de las que he leido solamente dos.

Aunque en menor medida me voy a ocupar también de las definiciones correspondientes a los numerales en estos otros contextos:

14. Dos es un número par

15. Veinte está formado por un dos y un cero

en los que por cierto tan solo 14 aceptaría propiamente ese tipo de definición.

\subsection{ACEPCIONES}

$Y$ es que, independientemente de que los numerales cardinales puedan usarse como ordinales, por ejemplo en 


\section{Rosita vive en el piso diecinueve de un rascacielos neoyorquino,}

y de que, a su vez, a cada uno puedan corresponderle otros sentidos particulares y exclusivos, todos ellos se utilizan también como nombres de los números, entendidos no solo en su realidad abstracta o matemática, sino también como signos, guarismos o cifras consistentes en unos determinados rasgos gráficos, significados estos que, como puede verse, se manifiestan, respectivamente, en los ejemplos 14 y $15 .^{2}$

Así pues, una palabra como cinco no solo sirve para representar una determinada cantidad con abstracción de los tipos de objetos contables a que pueda referirse, sino también puede indicar el signo gráfico - por ejemplo, 5 en el sistema arábigo, o v en el romano- utilizado asimismo para representar esa misma cantidad. Esto quiere decir que las representaciones gráficas cinco y $5 \mathrm{o} \mathrm{V}$ responden a dos códigos gráficos distintos e independientes: alfabético el primero, pues implica un análisis del significante fónico, cuyos fonemas representa mediante grafemas o letras, e ideológico el otro, puesto que la figura gráfica no conecta para nada con la lengua oral, sino, como ésta, directamente con el contenido. Es decir, en esquema tenemos:

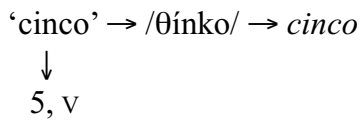

Ahora bien, por tratarse de sistemas gráficos pueden, al menos en teoría, sustituirse mutuamente, de modo que una cantidad cualquiera puede representarse tanto en letra como en números o cifras; o sea,

\section{El número premiado acaba en cinco $=$ El número premiado acaba en 5}

Realmente en las normas ortográficas no existen reglas específicas que regulen el uso de uno y otro sistema. Pueden, eso sí, marcarse tendencias o costumbres, como las señaladas recientemente por la Academia en su $D P D$ (s. v. números), que obedecen a varios factores como el tipo de texto, la complejidad del número o el contexto de uso. Así, por ejemplo, son preferibles las cifras en textos científicos con operaciones matemáticas, pero se prefiere en general la representación con letras en textos literarios, a menos que se trate de cantidades muy complejas. No hace falta señalar, por lo demás, que, cuando leemos, convertimos en fonemas -transcodificamostanto los signos gráficos de letras como, naturalmente, los expresados mediante cifras.

Volviendo, pues, a los significados de los numerales, cabe señalar tres acepciones distintas, ${ }^{3}$ que pueden ejemplificarse mediante los siguientes enunciados:

${ }^{2}$ Esta situación la ha expresado muy bien Marcos Marín (1990: 105, y 1999: 1191), cuando dice: «El concepto de número supone una abstracción y su representación un doble código, el que representa al número, es decir, la cifra, o el que representa al nombre del número; el primero es un signo aritmético, mientras que el segundo es un signo lingüístico y se atiene a las reglas de cada lengua, aunque también la representación del primero por su cifra forme parte, de algún modo, de lo lingüístico».

Convendría añadir en todo caso que el signo aritmético, como objeto de la realidad que es, recibe también un nombre, el mismo que corresponde al número independientemente de su representación.

${ }^{3}$ En realidad no se trata de acepciones en sentido estricto ( $c f$. Porto Dapena 2002: 196), esto es, entendidas como invariantes semánticas o significados de lengua. Por el contrario, habría que hablar más bien de subacepciones o puras variantes de uso, pues en todos los casos corresponden a un mismo paradigma. 
18. Felipe tiene dos hermanos (pronombre adjetivo), uno de ellos es ciego (pronombre sustantivo)

19. El trece, para muchos, es un mal número (sustantivo, nombre del número)

20. Trece se escribe con un uno y un tres (sustantivos, nombres de los guarismos).

Es curioso señalar, sin embargo, que los diccionarios -empezando por el $D R A E$ - no realizan en los artículos correspondientes a los numerales semejante separación tripartita, pues o bien reducen las tres acepciones a una sola (así el $D U E$ ), o, como es práctica habitual, se confunden las dos últimas en un solo uso sustantivo. La única excepción viene representada por el $D E A$, que, además, incluye -pienso que innecesariamente- una acepción pronominal correspondiente al empleo sustantivado del adjetivo, por elisión del sustantivo y con función anafórica o catafórica. ${ }^{4}$

\subsection{El PARADIGMA DE LOS NUMERALES ESPAÑOLES}

A nadie se le oculta que los números naturales enteros constituyen una serie infinita y todos ellos son a su vez susceptibles de ser expresados no solo matemática, sino también lingüísticamente. Ahora bien, si infinitos son los números, infinitos habrán de ser también los signos que los representan, lo que no quiere decir, sin embargo, que éstos hayan de corresponder a un paradigma asimismo infinito y, por consecuencia, imposible de ser registrado en su totalidad dentro de la nomenclatura de un diccionario. Por el contrario, el paradigma tiene carácter finito, al estar constituido por unos cuantos elementos que, gracias a unas reglas sintácticas muy sencillas, admiten, en cambio, posibilidades infinitas de combinación. Y así, como es bien sabido, el sistema aritmético arábigo está constituido en realidad por tan solo diez guarismos $(0,1,2,3,4,5,6,7,8$ y 9), a partir de los cuales se pueden expresar innumerables cantidades. Por su parte el sistema numeral lingüístico, aunque más complejo, está asimismo constituido por unos cuantos signos, susceptibles también de combinaciones sintagmáticas infinitas. Esto supuesto, hay que distinguir entre numerales paradigmáticos, es decir, los que verdaderamente constituyen el sistema o paradigma, como tres, diez o veinticuatro, y numerales sintagmáticos, los formados aplicando a aquéllos las reglas combinatorias, como ciento treinta y dos o cuarenta mil. ${ }^{5}$ No hace falta señalar que, obviamente, de la nomenclatura del diccionario habrán de formar parte exclusivamente los numerales paradigmáticos, aun cuando tampoco en este aspecto los diccionarios presentan, como veremos, una total coincidencia.

Para empezar, conviene tener en cuenta que el español posee dos sistemas lingüísticos de numerales, fónico y gráfico, que no guardan entre sí un absoluto paralelismo, pues, por ejemplo, mientras dieciocho es un numeral paradigmático -se escribe como una sola palabraen el gráfico, tiene un evidente carácter sintagmático en el fónico, pues no responde más que a la coordinación copulativa de diez y ocho, y, por lo tanto, en este sentido no tiene un estatus diferente al de treinta y ocho, que también es sintagmático gráficamente. Esta distinción es importante porque, como es obvio, el diccionario registra vocablos escritos y, consiguientemente, los numerales que ha de incluir en su nomenclatura serán los del paradigma gráfico.

${ }^{4}$ Tal separación no se justifica, a mi juicio, dado que el carácter pronominal también les corresponde a los numerales en su uso meramente adjetivo, pues se trata de palabras gramaticales con valor nominal. Así pues, tan pronombre es dos en Tengo dos coches como en Tengo dos. Véase Porto Dapena (1986: 7).

${ }^{5}$ Véase Porto Dapena (1986: 157). 
Lo mismo que el fónico, el paradigma gráfico está, por otro lado, integrado, como es sabido, por formas simples, derivadas y compuestas ${ }^{6}$ Éstas últimas están constituidas por conglomerados procedentes de numerales inicialmente sintagmáticos; como pueden ser veinticuatro o trescientos, mientras que en la constitución de las derivadas entra algún elemento afijal, como en treinta o catorce, por ejemplo. En una visión totalmente sincrónica nuestro paradigma de numerales es el siguiente:

a) Formas simples: cero, un(o), dos, tres, cuatro, cinco, seis, siete, ocho, nueve, diez, cien(to) y mil.

b) Formas derivadas: Cabe distinguir

- Con el sufijo -ce, que indica suma de diez: once, doce, trece, catorce y quince.

- Con el sufijo enta o-inta,-inte, que representa la multiplicación por diez: veinte, treinta, cuarenta, cincuenta, sesenta, setenta y noventa.

c) Formas compuestas: Tenemos también dos variedades morfológicas:

- Por coordinación copulativa, indicando suma: dieciséis, diecisiete, dieciocho, diecinueve; veintiuno, veintidós, veintitrés, veinticuatro, veinticinco, veintiséis, veintisiete, veintiocho y veintinueve. No hace falta advertir que solo los correspondientes a veinti- se corresponden con numerales del paradigma fónico.

- Por yuxtaposición, indicando multiplicación: doscientos, trescientos, cuatrocientos, quinientos, seiscientos, setecientos y novecientos.

Teniendo en cuenta que este paradigma de numerales no permitiría expresar cantidades más allá de novecientos noventa y nueve mil novecientos noventa y nueve, se echa mano de un sistema complementario constituido por una serie de sustantivos colectivos de cantidad precisa, a saber: millón, billón, trillón, cuatrillón y quintillón. A este mismo paradigma pertenecen, obviamente, decena, docena, veintena y millar, entre otros.

Este sistema de numerales se complementa, por lo demás, con una regla sintáctica muy sencilla para la formación de numerales sintagmáticos, y que se puede indicar así: un numeral se suma al siguiente cuando éste es menor, y, por el contrario, se multiplica por él cuando es mayor. Así, treinta y cinco equivale a $30+5$; tres mil viene a ser 3 x 1000, y ciento treinta y dos mil quinientos ochenta y tres se representará aritméticamente por

$$
[(100+30+2) \times 1000]+500+80+3
$$

Si comparamos ahora las nomenclaturas de los diccionarios al uso, observaremos, como ya señalé más arriba, que no hay una total coincidencia a la hora de registrar los numerales. La mayoría, desde luego, incluye entre sus entradas, como era de esperar, a todos los elementos del paradigma gráfico que acabamos de describir. Tan solo el $D E A$ y el GDUEA suprimen los comprendidos entre veintiuno y veintinueve, registrando en su lugar la forma veinti-, que clasifican como elemento prefijal, advirtiendo que se junta con numerales del uno al nueve para formar otros compuestos. La solución no me parece muy correcta, puesto que el segmento veinti- no constituye, desde luego, ningún sufijo del español, y, por otra parte, no es coherente con la que se da, por ejemplo, a los numerales -morfológicamente idénticos-que comienzan por dieci-, al no registrar a esta como entrada. Lo coherente en todo caso hubiera sido registrar 
tan solo los numerales simples junto con los componentes utilizados en los compuestos y derivados.

\section{LOS DEFINIENTES}

Delimitados los definienda o elementos de la macroestructura que van a ser objeto del especial tipo de definición que aquí me he propuesto estudiar, es el momento de referirnos a ésta, la cual, como ya queda dicho, no consiste en otra cosa que en utilizar como definiens lo que no viene a ser más que la formulación, en palabras, de una operación aritmética, representada normalmente por una suma o multiplicación de unidades. En principio, siguiendo este procedimiento, un numeral, independientemente considerado, puede ser definido, según ya queda señalado, de múltiples formas, todas idénticamente válidas; pero, habida cuenta de que los elementos definidos constituyen un paradigma o conjunto estructurado de elementos y, al mismo tiempo, aquéllos actúan como definientes, las respectivas definiciones no pueden ser independientes unas de otras, lo que quiere decir que tienen que guardar entre sí una coherencia interna que, entre otras cosas, evite circularidades como la que se produciría, por ejemplo, si definiéramos:

tres. Cuatro menos uno

cuatro. Tres y uno

por poner tan solo un ejemplo muy simple. No es, pues, absolutamente indiferente la elección que se haga de la operación matemática a la hora de formular un definiens, porque, como ocurre siempre que se definen los miembros de un paradigma, ${ }^{7}$ unas definiciones condicionan a las otras: en realidad las definiciones correspondientes deben constituir también un sistema homogéneo y coherente, que, por cierto, no siempre encontramos en los diccionarios.

\subsection{Procedimientos AdOPTAdOS POR ALGUNOS DiCCIONARIOS}

Antes, no obstante, de proponer el que, a mi modo de ver, debería constituir un sistema de definiciones adecuado para el caso de los numerales cardinales y referirme, a su vez, a las características formales de la definición de cálculo aritmético, vamos a ver cuáles son los procedimientos adoptados por algunos de los diccionarios más representativos y usuales del español de hoy.

\subsubsection{El DEA}

A este respecto cabe señalar que probablemente el diccionario que utiliza el procedimiento más sencillo a la hora de definir los numerales es el $D E A$ de $\mathrm{M}$. Seco, O. de Andrés y G. Ramos, y que consiste en la indicación de la suma de la unidad al número inmediato anterior -en la serie ordenada que constituyen los números naturales- al que actúa como definiendum, de modo que tendremos:

${ }^{7}$ Esto habla, obviamente, a favor del procedimiento -adoptado por cierto en la elaboración del Diccionario "Coruña"- de realizar la labor lexicográfica por paradigmas léxicos y no, como ha sido la práctica habitual hasta ahora, siguiendo el puro orden alfabético de las entradas. 


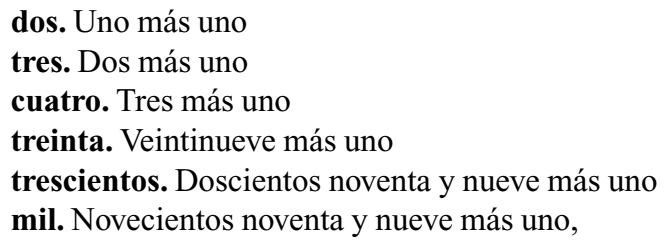

etc., Tan solo en el caso de los sustantivos millón, billón, trillón, cuatrillón y quintillón $n^{8}$ utiliza un procedimiento diferente:

millón. Cantidad de mil millares

billón. Cantidad de un millón de millones

trillón. Cantidad de un millón de billones

cuatrillón. Cantidad de un millón de trillones

quintillón. Quinta potencia del millón.

Es decir, en los cuatro primeros casos se define con el sustantivo cantidad, del que se hace depender un complemento consistente en la formulación de una suma que viene a equivaler a una multiplicación; esto es, 1000 x 1000, 1000000 x 1000000, etc., mientras que en el último caso se echa mano directamente -esto es, sin acudir al sustantivo cantidad - de una fórmula exponencial: $1000000^{5}$. Este diferente tratamiento, por lo demás, se justificaría por el hecho de tratarse de sustantivos numéricos colectivos, frente a los demás numerales, de carácter eminentemente adjetivo.

\subsubsection{El DRAE}

Desde luego los procedimientos más frecuentes empleados en la definición de los numerales son los adoptados por el $D R A E$, de donde pasaron a otros muchos diccionarios, entre los que debo destacar el $D U E$, aunque con ligeras diferencias, como veremos.

En primer lugar, el $D R A E$ utiliza la suma en los números del dos al diecinueve, y de la siguiente manera: hasta once adoptando como sumandos la unidad y el número inmediato inferior al definiendum, y a partir de doce hasta diecinueve y, luego, de veintiuno a veintinueve, añadiendo a diez o veinte el número correspondiente a las unidades restantes. Así,

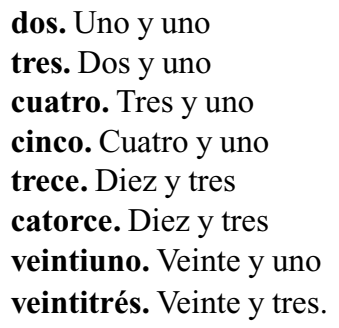

Por su parte los numerales correspondientes a las decenas (veinte, treinta, cuarenta, etc.), centenas (doscientos, trescientos, quinientos...) y millar son definidos en el DRAE mediante lo que puede considerarse la indicación de una operación de multiplicación, es decir,

\footnotetext{
${ }^{8}$ Curiosamente, este último numeral no es recogido por ningún otro diccionario.
} 
veinte. Dos veces diez

treinta. Tres veces diez

ciento. Diez veces diez

trescientos. Tres veces cien

mil. Diez veces ciento.

Como puede verse, en las decenas y cien(to) consiste en la multiplicación de diez por el número de decena, y en las centenas y mil en la de cien por el número de centena. Como veremos más adelante, desde el punto de vista lingüístico, la multiplicación puede expresarse o bien mediante un sintagma constituido por los números que se multiplican relacionados por la preposición por (o la expresión multiplicado por) o bien, como es este el caso, indicando la cantidad de veces que un número se suma a sí mismo. Cabe también, naturalmente, utilizar un sustantivo colectivo, indicador de cantidad numérica (por ejemplo, decena, millar, millón, etc.) precedido de un adjetivo numeral, representante del multiplicador. A una multiplicación, pues, podremos pensar que corresponde asimismo la definición de millón:

millón. Mil millares,

donde, como se ve, se utiliza un colectivo numérico, esto es, millar, por pertenecer a esta misma clase el definiendum, complementado con un adjetivo numeral, que viene a corresponder al multiplicador. En la misma línea hay que situar la definición de los demás numerales colectivos:

billón. Un millón de millones

trillón. Un millón de billones

cuatrillón. Un millón de trillones ${ }^{9}$

donde, como puede verse, se utiliza la fórmula, también multiplicativa, un millón + de $+n u ́$ mero por el que se multiplica.

\subsubsection{El DUE}

Por lo que se refiere al $D U E$, ya hemos dicho que emplea los mismos procedimientos que el $D R A E$, aunque con algunas modificaciones -no siempre felices, desde luego-, de las que la más importante es que $\mathrm{M}^{\mathrm{a}}$. Moliner formula las definiciones en lo que viene denominándose metalengua de signo, al partir de la clasificación o subcategorización del definiendum como "numeral cardinal" e incluyendo dentro del correspondiente enunciado la paráfrasis definicional, en vez de adoptarla directamente como definiens, que es como procede el $D R A E$. Pero fijándonos exclusivamente en la parte parafrástica, ésta presenta las siguientes características:

a) En primer lugar, la definición mediante suma de la unidad al número inmediato inferior comprende, como en el $D R A E$, a los números del dos al once, a partir del cual se van sumando a diez los números correspondientes a las unidades, con la excepción de diecinueve, en cuya definición se vuelve, curiosamente, a sumar la unidad al número inmediato inferior, esto es, al dieciocho, rompiéndose así la homogeneidad del sistema definicional. Así, 


\begin{abstract}
dos. Número cardinal equivalente a uno más uno tres. Número cardinal equivalente a dos más uno cuatro. Número cardinal equivalente a tres más uno doce. Número cardinal equivalente a diez más dos trece. Número cardinal equivalente a diez más tres catorce. Número cardinal equivalente a diez más cuatro diecinueve. Número cardinal equivalente a dieciocho más uno.
\end{abstract}

Inopinadamente, sin embargo, seis, saliéndose claramente de la regla, se define seis. Numeral cardinal: cuatro y dos

en construcción copulativa, en lugar de la fórmula utilizada en los otros casos con más.

b) Por su parte veinte y treinta se definen también mediante una suma, de diez más diez en el primer caso, y de veinte más diez en el segundo, pasándose a continuación a definir todos los demás números de decenas -y el de ciento- siguiendo el procedimiento académico, es decir, mediante multiplicación de diez por el número de decena. Así,

veinte. Número cardinal equivalente a diez más diez

treinta. Número cardinal equivalente a veinte más diez cuarenta. Número cardinal equivalente a cuatro veces diez cincuenta. Número cardinal equivalente a cinco veces diez ciento. Numeral cardinal: diez veces diez.

Curiosamente en el caso de sesenta se invierten los términos, faltando nuevamente a la homogeneidad:

sesenta. Número cardinal equivalente a diez veces seis.

c) El procedimiento de suma se emplea también, como en el $D R A E$, añadiendo el número de unidades a veinte en los numerales del veintiuno al treinta, éste inclusive como queda visto. Y se vuelve a emplear, en este caso a diferencia del DRAE, en doscientos y trescientos, que se definen mediante la suma de cien al número de centena anterior; es decir,

veintiuno. Veinte más uno

veintidós. Veinte más dos

veintitrés. Veinte más tres

doscientos. Cien más cien

trescientos. Doscientos más cien,

pasándose en los demás casos -incluido mil-al procedimiento mediante multiplicación:

cuatrocientos. Cuatro veces cien

quinientos. Cinco veces cien

novecientos. Nueve veces cien

mil. Diez veces cien. 
d) Finalmente, por lo que se refiere a los sustantivos billón, trillón y cuatrillón, coincide totalmente con la Academia.

\subsubsection{El GDUEA}

En lo que toca a las definiciones de los numerales, este diccionario presenta una gran heterogeneidad o falta de regularidad debido - es de suponer- a la multiplicidad de personas que intervinieron en su redacción sin ninguna orientación específica al respecto. Independientemente de que alternan las definiciones redactadas en primera metalengua, como, por ejemplo,

seiscientos. Seis veces ciento

con las expresadas - en la mayoría de los casos- en segunda metalengua, ${ }^{10}$ como

quinientos. Se dice de las cosas o personas que están en un número igual a cien multiplicado por cinco,

se utilizan, a veces en un mismo artículo, diversos procedimientos y cálculos aritméticos para definir los numerales. Así, en catorce se dan hasta tres posibilidades de operaciones aritméticas -en este caso, de suma-distintas:

catorce. Numeral $\mathrm{u}$ ordinal ${ }^{11}$ que representa la cantidad resultante de sumar, $p$ ej diez y cuatro (o seis y ocho, nueve y cinco, etc.).

A veces se utilizan dos recursos o tipos de operaciones o cálculos aritméticos diferentes, como en

setecientos. Número que equivale a seiscientos noventa y nueve más uno, o siete veces cien.

Por primera vez, en fin, encontramos empleado incluso como recurso de definición una operación de resta, que como alternativa a la suma se da en las definiciones de los numerales ocho, nueve y once:

ocho. Numeral que designa el conjunto formado por siete unidades más una o de nueve unidades menos una

nueve. Numeral que designa el conjunto formado por ocho unidades más una, o diez unidades menos una

once. Numeral que designa el conjunto formado por diez unidades más una, o de doce unidades menos una.

\footnotetext{
${ }^{10}$ Añádase, además, que en la utilización de la metalengua de signo se adoptan a su vez fórmulas muy distintas, pues, al lado del poco elegante, por innecesario, «dícese de», los definienda son definidos como numerales unas veces, como números otras, o incluso como cantidades, procedimiento sin duda inadecuado en estos dos últimos casos, pues, claro está, no es indiferente decir de una palabra que es un numeral, un número o una cantidad.

${ }^{11}$ Resulta por cierto chocante esta caracterización, en la que parece darse a entender que un ordinal no es numeral (ii!).
} 
Desde luego, el recurso matemático utilizado para la definición de los numerales del dos al once es básicamente el mismo que el del DRAE y DUE, consistente en la suma de la unidad al número más bajo inmediatamente anterior al definido, aunque, como acabamos de ver, ese procedimiento convive en las definiciones de ocho, nueve y once con el de una operación de sustración. Ese mismo procedimiento de adición de una unidad se aplica asimismo -aunque atípicamente y en contraposición con otros numerales de decena y centena- en las definiciones de veinte, setenta y setecientos:

veinte. Numeral equivalente a diecinueve más uno

setenta. Número que equivale a sesenta y nueve más uno, o diez veces siete

setecientos. Número que equivale a seiscientos noventa y nueve más uno, o siete veces cien.

También coinciden con el DRAE y DUE las definiciones de doce a diecinueve, consistentes en sumar a diez el número correspondiente a las unidades, es decir,

doce. Numeral correspondiente a la cifra de diez más dos

trece. Numeral equivalente a la suma de diez más tres,

etc. con la excepción, según observamos, de catorce, donde se ofrecen, como hemos visto, otras posibilidades.

Como en el caso del $D E A$, se obvia el registro de los numerales entre veintiuno y veintinueve, introduciendo como entrada la forma veinti-, que se clasifica -repito que inadecuadamente- como prefijo. Por lo que se refiere a los demás numerales correspondientes a decenas, centenas junto con mil, millón, billón, trillón y cuatrillón, el procedimiento empleado es el de la multiplicación, con la excepción de cuarenta, cincuenta y, en parte, según ya hemos visto, setenta y setecientos Así:

treinta. Numeral equivalente a multiplicar diez por tres

sesenta. Cantidad equivalente a seis veces diez

doscientos. Se dice del numeral ordinal [sic] correspondiente a la cifra de dos veces cien

novecientos. Numeral que designa el conjunto formado por nueve grupos de cien unidades

mil. Numeral que designa el conjunto formado por diez grupos de cien unidades

frente, en cambio, a

cuarenta. Numeral que representa la cantidad resultante de sumar, $p$ ej treinta y diez (o veinte y veinte, etc.)

cincuenta. Numeral que representa la cantidad resultante de sumar, $p$ ej cuarenta y diez (o treinta y veinte, etc.),

donde el procedimiento empleado es, como se ve, la suma.

\subsubsection{Diccionarios Clave, Salamanca $y$ Anaya}

Lugar aparte ocupan, en el conjunto de los diccionarios del español, el Clave, Salamanca y Anaya, por las innovaciones -no muy acertadas, por cierto- que, en la definición de los numerales, introducen en comparación con la tradición anterior y que, al parecer, no tienen 
otro objetivo que evitar precisamente las definiciones de cálculo aritmético. Y así, por ejemplo, en el Clave encontramos

\author{
uno. Número 1 \\ dos. Número 2 \\ veinte. Número 20 \\ doscientos. Número 200.
}

En el Salamanca, por su parte,

uno. Cantidad que representa la cifra 1

dos. Cantidad que representa la cifra 2

veinte. Cantidad que representa la cifra 20

doscientos. Cantidad que representa la cifra 200

etc. Y, finalmente, en el Anaya:

uno. Nombre del número 1

dos. Indica que el nombre al que acompaña o al que sustituye está 2 veces.

Para empezar, las definiciones se fundamentan en la equivalencia del definido con una cifra expresada en el correspondiente número arábigo, de modo que, en vez de una verdadera definición, nos encontramos ante una simple transcodificación gráfica de un signo expresado en letras (el definiendum) a una cifra o signo aritmético (el definiens), que, además, como no forma parte de la nomenclatura del diccionario, produce la consiguiente pista perdida. Esto, naturalmente, sin salirnos del nivel puramente gráfico, en el que, como es lógico, se sitúa todo diccionario; pero notemos que la cosa se agrava todavía más al pasar, en la lectura, tales signos a lenguaje oral: la consiguiente tautología entre definiendum y definiens se hace inevitable y patente; es decir, de

\title{
uno es 1
}

se pasa, obviamente, a

/úno és úno/

En definitiva, el procedimiento no parece buscar otro objetivo que escamotear una definición.

Refiriéndonos en concreto al Clave, debemos recordar que de las tres acepciones que señalábamos al principio tan solo la tercera aparece claramente definida -aquí como segunda-, frente a las otras dos, que, totalmente confundidas, se registran como primera acepción. Cabe observar, no obstante, que la definición de esta primera acepción, expresada bajo la fórmula muy sencilla de número + cifra o signo aritmético (fórmula evidentemente ambigua, pues el sustantivo número puede interpretarse como entidad abstracta y como cifra), corresponde en todo caso a lo que más atrás considerábamos segunda acepción y no a su valor pronominal adjetivo, que aparece, sin embargo, en los ejemplos. 
No se puede decir lo mismo en este sentido del Anaya, donde aparece muy claramente separada, como primera, la acepción pronominal de la de entidad numérica, que se registra en segundo lugar, ahora bajo la fórmula nombre del número + cifra o signo aritmético:

dos [...]. Nombre del número 2

bien es verdad que en este caso hay que hablar asimismo de ambigüedad, pues tampoco sabremos si se trata del nombre de la entidad abstracta o, más bien, del signo aritmético 2, confundiéndose así nuestra segunda y tercera acepción. Debemos señalar, por otro lado y a propósito de la definición correspondiente a la acepción pronominal, que se contraviene visiblemente en este caso el principio de que el definido no puede entrar en el definiens, cosa que se puede ver, por ejemplo, en

cuarenta. Indica que el nombre al que acompaña o al que sustituye está 40 veces,

donde el 40 del definiens desempeña la función adjetiva que se atribuye al definiendum y, por lo tanto, se trata, lógicamente, del mismo signo. Por otro lado -y dicho sea de paso- la redacción deja además bastante que desear, pues lo que "está 40 veces" no es el nombre, sino, en todo caso, lo que éste representa. ${ }^{12}$ Digamos, en fin, que este diccionario no presenta una absoluta regularidad en el tratamiento de los numerales y que, frente al Clave y el Salamanca, utiliza también, aunque excepcionalmente, la definición de cálculo aritmético; así, en

ocho. Siete más uno

catorce. Diez más cuatro

quince. Signo que representan el valor de diez más cinco.

Totalmente regular es, por su parte, el Diccionario "Salamanca", que reduce las tres acepciones a una sola, definida siempre bajo una sencilla fórmula: cantidad que representa la cifra + signo aritmético correspondiente. La fórmula es, por lo demás, sintácticamente ambigua, pues no sabemos cuál es el sujeto y, por lo tanto, si es la cantidad lo que representa a la $c i$ fra o, como parecería más lógico, la cifra a la cantidad. En todo caso, la definición resulta aquí también escamoteada, pues nada se nos dice acerca del contenido semántico del definiendum, consistiendo, por otro lado, el definiens en una pura transcodificación que, además, lleva a una pista perdida, al no hallarse definidos en el diccionario los signos aritméticos a que se apunta.

\subsection{HACIA UNA HOMOGENEIZACIÓN EN LAS DEFINICIONES DE NUMERALES}

Visto todo lo anterior, me voy a permitir ahora hacer una propuesta de cómo, de un modo, a mi juicio, más claro, regular y coherente que el adoptado por la mayoría de los diccionarios actuales, deberían definirse los numerales, acudiendo para ello, entre otros recursos, sobre todo a la definición de cálculo aritmético, de cuyas características formales me voy también a ocupar de paso.

${ }^{12}$ No se trata de un lapsus ocasional, pues se repite la misma fórmula en los demás numerales. Sorprendentemente esta misma fórmula, con la misma redacción, es adoptada por otros diccionarios posteriores, concretamente por el Lema y el DUEAE. 


\subsubsection{Tipos y caracterización}

Pues bien, comenzando por esto último, recordemos que, aun cuando todo numeral, individualmente considerado y entendido al mismo tiempo como resultado de una operación o cálculo aritmético, admite, según ya queda dicho, un sinfín de posibilidades de definición, en la práctica esas posibilidades han de quedar necesariamente limitadas por las definiciones aplicadas a los demás numerales. Por otro lado, parece lógico pensar que la elección de tales posibilidades debe, al mismo tiempo, venir determinada en alguna medida por las características del propio sistema de numerales, de manera que no deben ser idénticas las definiciones en un sistema decimal, como es nuestro caso, que en otro que no lo sea. Por otro lado, no conviene perder de vista el principio científico de la sencillez - válido sin duda en la definición lexicográfica- en el sentido de que, entre dos tipos de cálculo aritmético, habrá de elegirse como definición el que resulte más elemental y sencillo; así es que de las posibilidades

dos. Uno más uno

dos. Cuadrado de tres menos siete

habría que elegir, indudablemente, la primera.

Habida cuenta de que la sucesión de los números naturales se produce en una progresión aritmética cuya razón es uno, probablemente la forma más sencilla de definir un número cualquiera consistirá en sumar esa unidad al inmediatamente inferior. Surge así la definición de cálculo aritmético por suma, definición que, lingüísticamente, puede adoptar dos formas: la coordinada, mediante la conjunción copulativa $y$, junto a la subordinada mediante la partícula más -de carácter átono, aunque acentuada gráficamente ${ }^{13}$-con función preposicional aditiva. ${ }^{14}$ Es decir,

cuatro. Tres y uno

cuatro. Tres más uno.

En cualquiera de los dos casos nos hallamos, claro está, ante una modalidad de definición aditiva, al consistir el definiens en la suma o adición del significado de dos o más palabras que actúan como verdaderos núcleos semánticos. Notemos, por otro lado, que en este caso particular los núcleos semánticos guardan a su vez una relación meronímica con el definiendum, del que en realidad expresan cantidades complementarias y parciales. No se trata, sin embargo, de definiciones meronímicas o participativas en el sentido definido en Porto Dapena (2002: 294) ni en M. B. Villar Díaz (2004: 397-402), puesto que en este caso lo definido no es un merónimo, como ocurre, por ejemplo, en

alero. Parte inferior del tejado,

${ }^{13}$ Cf. Seco, Diccionario de dudas, s. v. más.

${ }^{14}$ Como preposición la interpreta el propio DEA (s. v. más) y de semipreposición la tacha Santos Río (2003: $s$. $v$.). Aunque como operador lógico coincide con la conjunción $y$, desde el punto de vista gramatical ambas partículas dan lugar a dos sintagmas diferentes: coordinado con $y$, y subordinado con más, partícula que, a su vez, formará paradigma con menos (sustración o resta) y por (multiplicación), que asimismo funcionan como preposiciones. 
sino al contrario, un holónimo o totalidad, cuyas cantidades parciales o merónimos se utilizan como definientes. Y en este sentido, se parece más a la definición holonímica, a la que corresponde típicamente por cierto la de los numerales colectivos:

millar. Conjunto de mil unidades.

Este método de definición por suma de los numerales podría, desde luego, aplicarse a todos sin excepción, como hemos visto que hace el $D E A$. No obstante, esta fórmula convive, como hemos visto, en otros diccionarios con la de cálculo aritmético por multiplicación, que, lógicamente, no es más que una variedad de la de suma, de la adición de un número a sí mismo un determinado número de veces. Desde el punto de vista lingüístico puede expresarse de al menos tres modos distintos:

a) multiplicador + veces + multiplicando. Así,

treinta. Tres veces diez.

b) multiplicador (numeral adjetivo) + multiplicando colectivo (sustantivo), como es el caso de

mil. Diez millares.

c) multiplicando $+($ multiplicado $)$ por + multiplicador. Por ejemplo,

doscientos. Cien multiplicado por dos.

Cabe, por otro lado, hablar también de la definición por cálculo potencial cuando multiplicando y multiplicador coinciden, cosa que puede ocurrir en las definiciones de cien(to), $m i$ llón y billón. Así, según el DRAE,

ciento. Diez veces diez

millón. Mil millares

billón. Un millón de millones.

Se trata, en todo caso, de una mera variante de la de multiplicación, de la que, como se ve, no se distingue formalmente. Podría, no obstante, formularse de un modo específico, como, por ejemplo,

ciento. Cuadrado de diez (o Diez al cuadrado)

mil. Diez al cubo.

En la práctica -salvo alguna excepción que ya quedó señalada- no se utiliza la definición por sustración o resta, así como tampoco por división, que, sin embargo, podrían adoptarse en teoría. Por ejemplo,

cuatro. Cinco menos uno

cinco. Diez partido por dos. 
En todo caso, esta última forma de definición sería más apropiada para los numerales partitivos.

\subsubsection{Elección del tipo de definición}

Como ya dije más arriba, el procedimiento sin duda más sencillo de definición de los numerales sería, siguiendo la progresión aritmética de los números naturales, realizarla añadiendo siempre la unidad al número más bajo inmediato inferior en la serie. Ahora bien, tal procedimiento -que, como vimos, es el adoptado por el $D E A$ - sería adecuado si lo que pretendiéramos definir fuera la realidad, esto es, el conjunto infinito de números naturales, y no el sistema lingüístico, de tipo finito, tal como queda descrito más atrás. Lo esperable en este último caso sería que las definiciones estuviesen directamente formuladas en términos pertenecientes al propio paradigma y no, como ocurre, por ejemplo, en esta definición del $D E A$

trescientos. Doscientos noventa y nueve más uno

donde doscientos noventa y nueve constituye un numeral sintagmático y que, por lo tanto, no forma -ni formaría nunca- parte de la nomenclatura del diccionario. Por eso podríamos decir que existe una pista perdida en semejante definición, bien es verdad que esa pista perdida puede resolverse fácilmente aplicando el propio sistema de numerales, esto es, el paradigma y las reglas combinatorias.

A mi modo de ver, pues, lo ideal es que los definientes de los numerales estén a su vez constituidos exclusivamente por numerales paradigmáticos -esto es, por los mismos que se definen-, lo que nos llevará a desarrollar un sistema de definiciones cerrado -pero no circular-, aunque, por ello, algo más complejo que el abierto ad infinitum, como le ocurre al constituido por la mera suma de la unidad al número inmediato inferior. Este último procedimiento, en todo caso, sería aplicable únicamente a los numerales del dos al treinta, pero no en los demás, dado que, en este último caso, el numeral inmediato anterior tendría siempre carácter sintagmático.

Pero antes de seguir adelante, señalemos que un factor que a su vez no conviene perder de vista es la posibilidad que algunos numerales tienen de ser analizados morfológicamente y, por lo tanto, de ser al mismo tiempo definidos de acuerdo con ese análisis, esto es, mediante definiciones literales o morfosemánticas, ${ }^{15}$ de suerte que, en lugar de definir

quince. Catorce más uno,

podemos hacerlo de esta otra forma:

quince. Diez más cinco,

cuyos definientes diez y cinco se corresponden, respectivamente, con los elementos morfológi$\cos$ - ce y quin-. Esto supuesto, parece más apropiado definir, como hace el $D R A E$ y con él la mayor parte de los diccionarios, los numerales entre once y quince como la suma de diez más el número, de carácter variable, correspondiente a las unidades.

Ahora bien, notemos que podría no parecer éste el caso de definiciones como

15 Véase Porto Dapena (2002: 291). 


\author{
dieciséis. Diez y seis \\ diecisiete. Diez y siete \\ dieciocho. Diez y ocho \\ duecinueve. Diez y nueve
}

que cabría interpretar, a primera vista, más bien como variantes gráficas o meras reescrituras -sintética en el definiendum y analítica en el definiens - de los mismos numerales, cuando en realidad no es así ni mucho menos: notemos, efectivamente, que los correspondientes definientes no pueden responder más que a la formulación, al igual que en los casos anteriores, de una operación de suma (esto es, diez + seis, diez + siete, etc.), habida cuenta de que tales numerales no admiten escribirse analíticamente. ${ }^{16}$ Por eso, quizás, para evitar semejante interpretación tautológica, sería preferible utilizar en el definiens la modalidad subordinada en lugar de la coordinada; es decir, por ejemplo,

dieciséis. Diez más seis

Y, naturalmente, idéntica interpretación hay que dar a las definiciones literales correspondientes a los numerales del veintiuno al veintinueve; esto es,

veintiuno. Veinte y uno

veintidós. Veinte y dos,

etc., pues en este caso, además de que los definienda son numerales paradigmáticos no solo gráficamente como en el caso anterior, sino también desde el punto de vista fónico, ocurre exactamente lo mismo: tales numerales no admiten la grafía analítica y, por lo tanto, los correspondientes definientes responden a la formulación de una suma, que quizás también sería más adecuado expresar en la modalidad subordinada:

veintiuno. Veinte más uno.

Atendiendo también al plano morfológico es como surge la necesidad de adoptar la modalidad de definición por multiplicación, como es el caso de los numerales correspondientes a las decenas a partir de veinte y centenas; es decir,

veinte. Dos veces diez,

en que el elemento ve- se corresponde con el multiplicador dos, y el sufijo -inte (-inta o -enta en otros) se corresponde con el multiplicando diez. Otro tanto sucede con

doscientos. Dos veces cien

trescientos. Tres veces cien,

etc., en que el análisis morfológico es todavía más transparente.

${ }^{16} C f . D P D$ (s. v. numerales). 
Y, finalmente, a la misma situación obedecen las definiciones -sin duda también adecuadas- de los numerales colectivos mediante definición por multiplicación en que multiplicando y multiplicador es el mismo número, o lo que viene a ser equivalente, por cálculo potencial. O sea,

ciento. Diez por diez (o Diez decenas)

millón. Mil por mil (o Mil millares)

billón. Un millón de millones.

\subsubsection{Consideraciones finales}

Señalemos, ya para terminar, que el sistema de definiciones que acabamos de diseñar $-\mathrm{y}$ que, a grandes rasgos, coincide fundamentalmente con el empleado por el $D R A E$ - no será del todo adecuado si queremos mantener las tres acepciones que, según planteábamos al principio, ofrece este tipo de palabras. Y en efecto: las definiciones tal como quedan formuladas son todas, claramente de carácter conceptual, ${ }^{17}$ es decir, están formuladas, como es siempre lo ideal en un definición lexicográfica, en lo que ha dado en llamarse primera metalengua o metalengua de significado. Pero notemos que, desde el punto de vista del significado categorial, tales definiciones podrían servirnos tanto para caracterizar los pronombres numerales, como para los nombres de los números naturales. No así, claro está, para definir los signos aritméticos, de orden gráfico, con los que representamos a los dos primeros.

No hace falta explicar que esa ambigüedad es debida, precisamente, a la naturaleza de los definientes, representados por los propios numerales y que, por lo tanto, admiten -también en la definición- la doble interpretación, nominal y pronominal. Y esta es la razón-pienso- de que el $D R A E$, junto con otros muchos diccionarios, confunda en una sola esas dos primeras acepciones, a las que, según la interpretación que se dé a los numerales utilizados como definientes, se aplicarán en uno u otro sentido.

Una solución al problema podría consistir en señalar, como hace, por ejemplo, el $D E A$, los contextos o condiciones de uso en cada uno de los dos significados, advirtiendo, por ejemplo, antes de su definición, en la función adjetival, que precede a sustantivos en plural. Cabe también, como hacen otros, incluir el contexto dentro de la propia definición, formulada ahora en segunda metalengua o metalengua de signo, como podría ser, por ejemplo,

diez. Acompaña a un sustantivo para indicar que la realidad indicada por éste se toma en la cantidad equivalente a nueve más uno

donde el enunciado propiamente definicional o paráfrasis (en primera metalengua) aparece integrado dentro de un enunciado lexicográfico más amplio en metalengua de signo.

Semejantes soluciones no son, sin embargo, aceptables sencillamente porque la definición correspondiente al numeral adjetivo puede ser formulada perfectamente en primera metalengua -que es siempre la preferible- con tal de dotar al sintagma empleado como definiens de la correspondiente marca adjetival, objetivo que se consigue, como es sabido, ya sea convirtiendo dicho sintagma en una oración adjetiva o, quizás mejor en este caso, en un sintagma preposicional; es decir, 
doce. En la cantidad equivalente a diez más dos

cuyo definiens, por cierto, admite incluso conmutación:

Compró doce libros = Compró libros en la cantidad equivalente a diez más uno.

No hace falta señalar que, en el uso nuclear del pronombre, es decir, como adjetivo sustantivado, el numeral sigue teniendo la misma definición, aunque con la diferencia de que -como ocurre con todo adjetivo sustantivado- pasa a tener como referencia las personas, animales o cosas, previamente indicadas por el sustantivo elíptico.

En la acepción sustantiva, como indicadores de los números naturales, también estas palabras admiten definición conceptual, en este caso endocéntrica y sustancial, ${ }^{18}$ mediante la utilización de la palabra número como incluyente positivo o hiperónimo. Es decir,

doce. Número equivalente a diez más dos.

Ahora bien, puesto que los números naturales constituyen una serie o conjunto ordenado, cabe también adoptar un tipo de definición que, en lugar de poner de manifiesto el contenido cuantitativo, señale simplemente su posición dentro del conjunto. Tendríamos, pues, según eso, esta otra definición:

doce. Número que en la serie natural sigue al once,

que es la fórmula adoptada por el $D E A$.

Ni siquiera en la acepción correspondiente al nombre del signo aritmético hay siempre necesidad de definir en metalengua de signo o segunda metalengua, como ocurre, por ejemplo, en el caso siguiente:

doce. Nombre de la cifra 12 (en la escritura romana XII), que representa el número equivalente a diez más dos.

Pero también cabe la definición conceptual:

nueve. Signo aritmético que representa el número equivalente a ocho más uno. En caracteres arábigos es 9 y en romanos IX.

Pienso que lo adecuado será utilizar este último tipo para los guarismos simples o consistentes en una sola cifra, esto es, del 0 al 9, mientras que en los demás casos resulta más apropiado utilizar la definición funcional o en segunda metalengua. 


\section{REFERENCIAS BIBLIOGRÁFICAS}

ANAYA. Diccionario de secundaria y bachillerato de la lengua española (2000): Barcelona, Biblograf.

BoraO, J. (1859): Diccionario de voces aragonesas, Zaragoza, Imprenta y Librería de D. Calisto Ariño.

CASARES, J. (1959²): Diccionario idelológico de la lengua española, Barcelona, Gustavo Gili.

Clave. C. Maldonado, dir. (1997): Diccionario de uso del español actual, Madrid, SM.

Cuervo, R. J. (1886-1893): Diccionario de construcción y régimen de la lengua castellana, I y II, París, A. Roger y F. Chernoviz.

DEA. M. SeCo et al. (1999): Diccionario del español actual, Madrid, Aguilar.

DRAE. Real Academia Española (200122): Diccionario de la lemgua española, Madrid, Espasa-Calpe.

DUE. M. Moliner (1998²): Diccionario de uso del español, Madrid, Gredos.

DUEAE. P. Battaner Arias, dir. (2002): Diccionario de uso del español de América y España, Barcelona, Spes.

GDUEA. A.. SÁNCHEZ, dir. (2001): Gran diccionario de uso del español actual, Madrid, SGEL.

Lamano y Beneite, J. (2002 [1915]): El dialecto vulgar salmantino, Salamanca, Diputación de Salamanca, edic. facsimilar.

Lema. P. BATTANer, dir., (2001): Diccionario de la lengua española "Lema”, Barcelona, Spes.

Marcos Marín, F. (1990): «Lexicología en la formación del sistema de los nombres del número», Hispanica Posnaniensia, 1, pp. 105-131.

- (1999): «Los cuantificadores: los numerales», en I. Bosque y V. Demonte, dirs., Gramática descriptiva de la lengua española, Madrid, Espasa, 1, pp. 1189-1208.

MARTíneZ, J. A. (1989): El pronombre II: numerales, indefinidos y relativos, Madrid, Arco/Libros.

Porto DAPENA, J. Á. (1980): Elementos de lexicografia: el Diccionario de construcción y régimen de R. J. Cuervo, Bogotá, Instituto Caro y Cuervo.

- (1986): Los pronombres, Madrid, Edi-6.

- (2002): Manual de técnica lexicográfica, Madrid, Arco/Libros.

DPD. Real Academia Española y Asociación de Academias de la Lengua Española (2005): Diccionario panhispánico de dudas, Madrid, Santillana Ediciones Generales.

Salamanca. J. GutiérRez CuAdrado, dir. (2000): Diccionario "Salamanca” de la lengua española, Madrid, Santillana-Universidad de Salamanca.

Santos Río, L. (2003): Diccionario de partículas, Salamanca, Luso-Española de Ediciones.

SECO, M. (19869): Diccionario de dudas y dificultades de la lengua española, Madrid, Espasa-Calpe.

VILlar DíAz, M. B. (2004): Una nueva perspectiva en el análisis de la meronimia: el criterio lexicográfico, Salamanca, Universidad de Salamanca. 